\title{
BMJ Open Determinants of health system diagnostic delay of pulmonary tuberculosis in Gurage and Siltie zones, South Ethiopia: a cross-sectional study
}

\author{
Wako Golicha Wako (D , ${ }^{1}$ Abebaw Wasie, ${ }^{2}$ Zelalem Wayessa, ${ }^{3}$ Anteneh Fikrie ${ }^{1}$
}

To cite: Wako WG, Wasie A, Wayessa Z, et al. Determinants of health system diagnostic delay of pulmonary tuberculosis in Gurage and Siltie zones, South Ethiopia: a crosssectional study. BMJ Open 2021;11:e047986. doi:10.1136/ bmjopen-2020-047986

- Prepublication history for this paper is available online. To view these files, please visit the journal online (http://dx.doi. org/10.1136/bmjopen-2020047986).

Received 14 December 2020 Accepted 15 October 202

Check for updates

(C) Author(s) (or their employer(s)) 2021. Re-use permitted under CC BY-NC. No commercial re-use. See rights and permissions. Published by BMJ.

${ }^{1}$ Public Health, Bule Hora University, Bule Hora, Ethiopia

${ }^{2}$ Public Health, Wolkite University, Welkite, Ethiopia ${ }^{3}$ Midwifery, Bule Hora University, Bule Hora, Ethiopia

Correspondence to Mr Wako Golicha Wako; bwakot730@gmail.com

\section{ABSTRACT}

Background Unrecognised transmission of tuberculosis is a main contributor of high epidemic of tuberculosis in lowincome countries. Studies done in Ethiopia showed that delay in tuberculosis diagnosis and treatment is one of the major challenges to tuberculosis control programmes in the country. This study assessed factors which predict health system diagnostic delay of new pulmonary tuberculosis in Gurage and Siltie zones, South Ethiopia. Methods A health facility-based cross-sectional study was conducted among 204 adult patients with new pulmonary tuberculosis in Gurage and Siltie zones. Consecutive sampling technique was used to recruit participants. Data were collected by using a structured and pretested Amharic questionnaire. Data were entered into Epi-info V.7, processed and analysed by SPSS V.20. Health system diagnostic delay was dichotomised as either long or acceptable delay using median delay.

Results Median (IQR) patient and health system diagnostic delays are almost equal which are 20 (10-34.5) and 20.5 (8.2-56.2) days, respectively. Results from logistic regression show that presence of long patient delays (adjusted OR (AOR) $=2.85,95 \% \mathrm{Cl}: 1.44$ to 5.62 ; $\mathrm{p}=0.003$ ) in seeking care, presence of sputum smear examination ( $A O R=0.37,95 \% \mathrm{Cl}: 0.19$ to $0.75 ; p=0.005$ ) at the first visit to a health facility and multiple heath facility visit before diagnosis of tuberculosis $(A O R=4.95$, $95 \% \mathrm{Cl}: 1.98$ to $12.40 ; p=0.001$ ) were factors significantly associated with long health system diagnostic delay. Conclusions Long patient delay and multiple health facility visits are positively associated with long health system diagnostic delay; whereas sputum smear examination at the first contact with a health facility is negatively associated with long health system tuberculosis diagnostic delay.

\section{INTRODUCTION}

Tuberculosis (TB) is one of the oldest infectious diseases affecting human beings. It is caused by a bacterium called Mycobacterium tuberculosis, which mostly affects the lungs, though any body organ can be affected. The disease is transmitted by aerosolised respiratory droplets from persons with infectious pulmonary TB emitted during coughing, sneezing and talking. ${ }^{1}$

\section{STRENGTHS AND LIMITATIONS OF THIS STUDY}

$\Rightarrow$ All eligible patients visiting participating health facilities during data collection period were studied and this might have reduced selection bias.

$\Rightarrow$ Data about delays and continuum of healthcare provided were collected based on patients' recall, so recall bias cannot be excluded.

$\Rightarrow$ As data collectors were health professionals working at a health facility where patients with tuberculosis (TB) sought treatment and diagnostic services, social desirability bias might have affected accurate reporting of TB-related stigma, delays, service satisfaction and health-seeking behaviours.

$\Rightarrow$ Items used to assess TB-related stigma, service satisfaction and TB knowledge were not standardised and their reliabilities are unknown.

$\Rightarrow$ The cut-off point to classify diagnostic delay as acceptable and long delay is not standardised and the same defect applies to the current study.

TB continued to be a major cause of ill health, particularly in developing countries. Globally, an estimated 10 million new cases of TB and 1.4 million deaths from TB occurred in 2019. ${ }^{2}$ Approximately $8.2 \%$ of these TB cases were coinfected with HIV. ${ }^{2}$ TB annual incidence is declining very slowly over recent years. ${ }^{2}$ This decline in incidence is not sufficient to attain end TB strategy by $2020^{2}$ and Sustainable Development Goals' target of ending TB epidemic by $2030 .{ }^{3}$ Geographically, WHO Africa region shares the largest global TB burden next to Southeast Asia. Ethiopia is 1 of the 30 high TB burden countries. ${ }^{2}$

Unrecognised transmission of $\mathrm{TB}$ is the main contributor of high epidemic of TB in low-income countries. ${ }^{4}$ Limited capacity in diagnosis, treatment and infection control in healthcare and community settings favours continued transmission of the disease in low-resource settings. ${ }^{4}$ Community transmission of $\mathrm{TB}$ is a major setting of TB transmission, and it needs policy attention to combat disease transmission. ${ }^{4}$ 
However, it has been neglected so far. A communitybased intensive case finding is an effective and feasible strategy in reducing TB transmission. ${ }^{4}$ Early identification and treatment of pulmonary TB is crucial to a TB control programme. Early identification and prompt treatment of pulmonary $\mathrm{TB}$ can help in reducing community transmission. ${ }^{5}$

Risk of pulmonary TB transmission in a given community would proportionally increase with the time patients spend within the community without getting treatment. ${ }^{56}$ As the patients stay within the community for a longer time, the number of susceptible people who come in contact with them would increase proportionally. ${ }^{56}$ Moreover, the longer the time the patients spend with susceptible persons, the more likely those susceptible persons develop TB. ${ }^{56}$

Studies done in Ethiopia showed that delay in TB diagnosis and treatment is one of the major challenges to TB control programmes in the country. ${ }^{7-9}$ The studies reported high median total delay which ranges from 70 to 90 days. Delays in diagnosis of TB could be attributed to patients alone or health system alone or combination of both patients and health system delays. Patients' poor health-seeking behaviour influenced by a number of social, economic and demographic factors could delay diagnosis of potentially infectious pulmonary TB. Similarly, health system may cause delays in diagnosis of the disease. Health system delays represent a missed opportunity to diagnose pulmonary TB. Moreover, health system delay is believed to be more amenable to policy intervention than patient delay. A study done in Ethiopia showed that $63 \%$ of total delays in diagnosis of pulmonary TB were attributed to health system. ${ }^{9}$

In Ethiopia, few studies have been done to assess factors which predict health system diagnostic delay of pulmonary TB. Thus, this study assessed factors which predict health system diagnostic delay of new pulmonary TB in Gurage and Siltie zones, South Ethiopia.

\section{METHODS}

\section{Study design and area}

A health facility-based cross-sectional study was conducted among patients with new pulmonary TB in Gurage and Siltie zones, South Ethiopia from December 2016 to April 2017. The two zones share border with each other. Gurage zone's administrative town, Wolkite, is located 154 $\mathrm{km}$ southwest to Ethiopia's capital, Addis Ababa; whereas Siltie zone's administrative town, Worabe, is located 170 $\mathrm{km}$ southwest to the capital.

\section{Source population and study population}

Participants were adult patients 15 years old or above who were diagnosed with pulmonary TB and enrolled into treatment at selected health facilities within two zones; and categorised as new pulmonary TB according to the national TB programme of Ethiopia. All patients with new pulmonary TB receiving anti-TB treatment or/ and diagnosed at the selected health facilities during the study period were included.

\section{Sample size}

The sample size was calculated based on sample size calculation formula for cross-sectional study to test hypothesis for dichotomous outcome variable with the following assumptions: ratio of unexposed to exposed of 1 ; power of the study $90 \%$; confidence level of $95 \%$; type of health provider as exposure (government hospital vs private facility) and estimated proportion of the outcome (ie, health system diagnostic delay) among patients who visited a government hospital is 0.235 and the proportion of the outcome among patients who visited a private facility $0.447 .{ }^{8}$ The formula for required sample size from both groups (exposed and non-exposed) was:

$$
n=2 \times\left\{\left[\frac{Z 1-\frac{\alpha}{2}+(Z 1-\beta)}{p 1-p 2 / \sqrt{p}(1-p)}\right]\right\}^{2}
$$

Where $\mathrm{n}$ is sample size from each group to be compared; $\mathrm{Z} 1-\mathrm{a} / 2$ is two-tailed Z-score corresponding to $95 \%$ confidence level (1.96); Z1- $\beta$ is one-tailed Z-score corresponding to power of the study (1.28); p1 is proportion of the outcome among patients who visited a government hospital; p2 is proportion of the outcome among patients who visited a private health facility and $\mathrm{p}=\mathrm{is}$ average of p1 and p2. Then, the sample size was computed using Epi-info V.7 Statcalc, and a total of 206 patients with new pulmonary TB were planned to be studied.

\section{Sampling procedures}

Twelve health facilities (six from each zone) which reported higher number of patients with $\mathrm{TB}$ in the year before commencement of the study were selected to participate in the study. The study participants were enrolled consecutively into the study over a period of 5 months. Patients on anti-TB treatments or newly diagnosed at participating health facilities were studied until required sample size was attained. Patients were interviewed at the time of diagnosis or when they come for drug refill.

Data collection instruments and procedures

Data were collected by using a structured and pretested Amharic questionnaire adapted from relevant literature. Data collectors were health professionals working at TB units of participating health facilities.

\section{Study variables}

Independent variables include but not limited to sociodemographic and economic variables, health-seeking behaviour of patient, physical distance to health facilities, symptoms of TB, types of treatment sought at the first time, types of investigations done, type of health facilities visited, knowledge of TB, perceived stigma related to $\mathrm{TB}$ and perceived satisfaction with continuum of care.

Dependent variable is health system diagnostic delay. 


\section{Operational definitions}

Patient delay: a time interval between onset of perceived symptom/s and first visit to a health facility expressed in a day.

Health system diagnostic delay: a time interval between a patient's first visit to a health facility and confirmation of diagnosis of pulmonary TB expressed in a day.

Total diagnostic delay: a summation of patient delay and health system diagnostic delay.

Long patient delay: a patient delay longer than the median of the patient delay of the study participants.

Long health system diagnostic delay: a health system diagnostic delay longer than the median of the health system diagnostic delay of the study participants.

Onset of symptom: onset of perceived symptom/s of TB leading to visit to health provider/health facility.

Health facility: governmental or non-governmental or private health post/health centre/hospital/clinic.

\section{Measurement}

Health system diagnostic delay was assessed by asking patients to recall the duration of time in days from the first visit to a health facility to the day of TB diagnosis. The median duration of health system diagnostic delay was determined and used to classify health system diagnostic delay dichotomously as 'long delay' (greater than the median) and 'acceptable delay' (less than or equal to the median). Similarly, patient delay was assessed by asking patients to recall the duration of time in a day from perceived onset of symptom/s of the illness to the first contact with a health facility. The median patient delay was used to classify patient delay dichotomously into either 'long patient delay' (greater than the median) or 'acceptable patient delay' (less than or equal to the median).

Patients' satisfaction with continuum of care was assessed by six items, each having 5-point Likert scale response options. For each item, the largest score corresponds to the highest satisfaction and vice-versa. Then, the scores of all items were summed up to create satisfaction index of a participant, and the median of the satisfaction indices was determined. Finally, the median was used to classify satisfaction index dichotomously into either 'satisfied' or 'not satisfied' category.

TB-related stigma was assessed using seven items, each having 5-point Likert scale response options. For each item, the largest score (ie, 5) corresponds to the highest perceived level of stigma and vice-versa. All responses to the items were summed up for each participant to create stigma index. The median of the stigma indices was computed. Then, the median was used to classify stigma indices dichotomously into either 'stigmatised' or 'less stigmatised' category.

Patients' knowledge about TB was assessed by seven knowledge items. Respondents who correctly responded to all questions were classified as having good knowledge and others were classified as having poor knowledge.

\section{Data processing and analysis}

Data were entered into Epi-info V.7 and exported to SPSS V.20 for further processing. The data were cleaned, coded and analysed by SPSS V.20. Associations between independent variables and dependent variable were expressed by using OR and $p$ values. Bivariate logistic regression analysis was done separately for all independent variables to assess their association with the dependent variable. $P$ value less than or equal to 0.25 on the bivariate analysis was used to select candidate variables for further analysis by multivariate logistic regression. Adjusted ORs (AORs) and $p$ value of $<0.05$ on multivariate analysis were used to declare statistically significant association between the selected independent variables and the dependent variable.

\section{Data quality assurance}

Data collectors and supervisors were trained on how to collect data. A questionnaire was pretested on population with comparable sociodemographic characteristics with the studied population outside the sites where the current study was conducted. An adapted English questionnaire was converted into Amharic language and reconverted back into English by two independent language experts who were judged to be fluent in both languages, and necessary correction was incorporated into as needed.

\section{Patient and public involvement}

Patients were not involved at any stage of this study.

\section{RESULTS}

\section{Sociodemographic characteristics}

Two hundred six patients were planned to be studied. Two hundred four patients were successful interviewed providing a response rate of $99.0 \%$. Data of two patients were excluded because of major incompleteness of the interviews. Final data analysis was based on data of 204 patients. Mean age $( \pm \mathrm{SD})$ of respondents was $35.2( \pm 1.36)$ years. One hundred twenty-six $(61.8 \%)$ of respondents were male. Majority of respondents were followers of Orthodox Christianity and Islam representing 98 (48.0\%) and $89(43.6 \%)$ of the sample, respectively. Others, 17 (8.3\%), were Catholic and Protestant Christians. One hundred twenty $(58.8 \%)$ respondents were rural residents. Majority, 143 (70.1\%), of respondents were married and the remaining, $58(28.4 \%)$ and $3(1.5 \%)$, were single and widowed, respectively. Majority of respondents were farmers, $78(37.7 \%)$ and housewives, 38 (18.6\%).

\section{Presenting symptoms and health status of patients with pulmonary TB}

About 184 (90.2\%) respondents reported presence of cough at their first visit to a health facility. Among these, $66(35.9 \%), 99(53.8 \%)$ and $19(10.3 \%)$ reported dry cough, cough productive of non-bloody sputum and cough productive of bloody sputum, respectively. These 
Table 1 Presenting symptoms and health status of patients with pulmonary tuberculosis (TB) in Gurage and Siltie zones, South Ethiopia, June 2017

\begin{tabular}{|c|c|c|c|c|}
\hline Variable & Category & Frequency & Per cent & $95 \% \mathrm{Cl}$ of per cent \\
\hline \multirow{9}{*}{$\begin{array}{l}\text { Symptoms at first visit to health } \\
\text { facility* (multiple response } \\
\text { possible) }\end{array}$} & Dry cough & 66 & 32.3 & 26.0 to 39.2 \\
\hline & $\begin{array}{l}\text { Cough productive of non-bloody } \\
\text { sputum }\end{array}$ & 99 & 48.5 & 41.5 to 55.6 \\
\hline & Cough productive of bloody sputum & 19 & 9.3 & 5.7 to 14.2 \\
\hline & Chest pain & 131 & 64.2 & 57.2 to 70.8 \\
\hline & Shortness of breath & 91 & 44.6 & 37.7 to 51.7 \\
\hline & Fever & 112 & 54.9 & 47.8 to 61.9 \\
\hline & Weight loss & 113 & 55.4 & 48.3 to 62.3 \\
\hline & Night sweat & 127 & 62.2 & 55.2 to 68.9 \\
\hline & Others & 9 & 4.4 & 2.0 to 8.2 \\
\hline \multirow{9}{*}{$\begin{array}{l}\text { Symptoms reported at health } \\
\text { facility that diagnosed TB* } \\
\text { (multiple response possible) }\end{array}$} & Dry cough & 67 & 32.8 & 26.4 to 39.7 \\
\hline & $\begin{array}{l}\text { Cough productive of non-bloody } \\
\text { sputum }\end{array}$ & 100 & 49.0 & 42.0 to 56.1 \\
\hline & Cough productive of bloody sputum & 29 & 14.2 & 9.7 to 19.8 \\
\hline & Chest pain & 135 & 66.2 & 59.2 to 72.6 \\
\hline & Shortness of breath & 105 & 51.5 & 44.4 to 58.5 \\
\hline & Fever & 124 & 60.8 & 53.7 to 67.5 \\
\hline & Weight loss & 137 & 67.1 & 60.3 to 73.6 \\
\hline & Night sweat & 137 & 67.1 & 60.3 to 73.6 \\
\hline & Others & 12 & 5.9 & 3.1 to 10.0 \\
\hline \multirow{2}{*}{$\begin{array}{l}\text { Sputum Acid fast bacillus (AFB) } \\
\text { smear results }\end{array}$} & Negative & 82 & 40.2 & 33.4 to 47.3 \\
\hline & Positive & 97 & 47.5 & 40.5 to 54.6 \\
\hline \multirow[t]{2}{*}{ HIV status } & Negative & 171 & 83.8 & 78.0 to 88.6 \\
\hline & Positive & 18 & 8.8 & 5.3 to 13.6 \\
\hline \multirow{5}{*}{$\begin{array}{l}\text { Existing medical condition } \\
\text { before onset of TB illness" } \\
\text { (multiple response possible) }\end{array}$} & Chronic cough & 93 & 45.6 & 38.6 to 52.7 \\
\hline & Chronic chest discomfort & 76 & 37.2 & 30.6 to 44.3 \\
\hline & Heart diseases & 14 & 6.9 & 3.8 to 11.2 \\
\hline & Physical disability & 8 & 3.9 & 1.7 to 7.6 \\
\hline & Other chronic illnesses & 21 & 10.3 & 6.5 to 15.3 \\
\hline \multirow[t]{3}{*}{ History of smoking } & Never smoked & 177 & 86.8 & 81.3 to 91.1 \\
\hline & Quitted smoking & 19 & 9.3 & 5.7 to 14.2 \\
\hline & Current smoker & 8 & 3.9 & 1.7 to 7.6 \\
\hline
\end{tabular}

*Per cent may not add up to $100 \%$.

patients made the first visit to a health facility after 20 median days of coughing (table 1).

\section{Health service utilisation patterns of patients with pulmonary TB}

Majority, 184 (90.2\%), of respondents sought first care from health facilities, whereas $14(6.9 \%)$ respondents either undertook self-medication or visited traditional healers before seeking care from a health facility. One hundred twelve $(54.9 \%)$ patients received sputum smear examination at the first visit to a health facility; of these, $50(44.6 \%)$ patients were smear positive and the results of $8(7.1 \%)$ patients were unknown. Thirty-four $(16.7 \%)$ patients received anti-TB treatment at their first visit to a health facility. Majority, 128 (62.7\%), of patients received non-mycobacterial antibiotics at the first visit to a health facility, whereas $24(11.8 \%)$ and $19(9.3 \%)$ patients received unspecified medicine and were referred to a higher health facility, respectively (table 2).

Accessibility of health facilities diagnosing new pulmonary TB The average frequency of health facility visit before diagnosis of pulmonary TB was 2.5 hours (IQR: 2-3). Majority $(64.7 \%)$ of patients were diagnosed at government health facilities. Seventy-seven $(37.7 \%)$ patients were diagnosed at primary hospitals. Regarding the distance travelled to 
Table 2 Health service utilisation patterns among patients with new pulmonary tuberculosis (TB) in Gurage and Siltie zones, South Ethiopia, June 2017

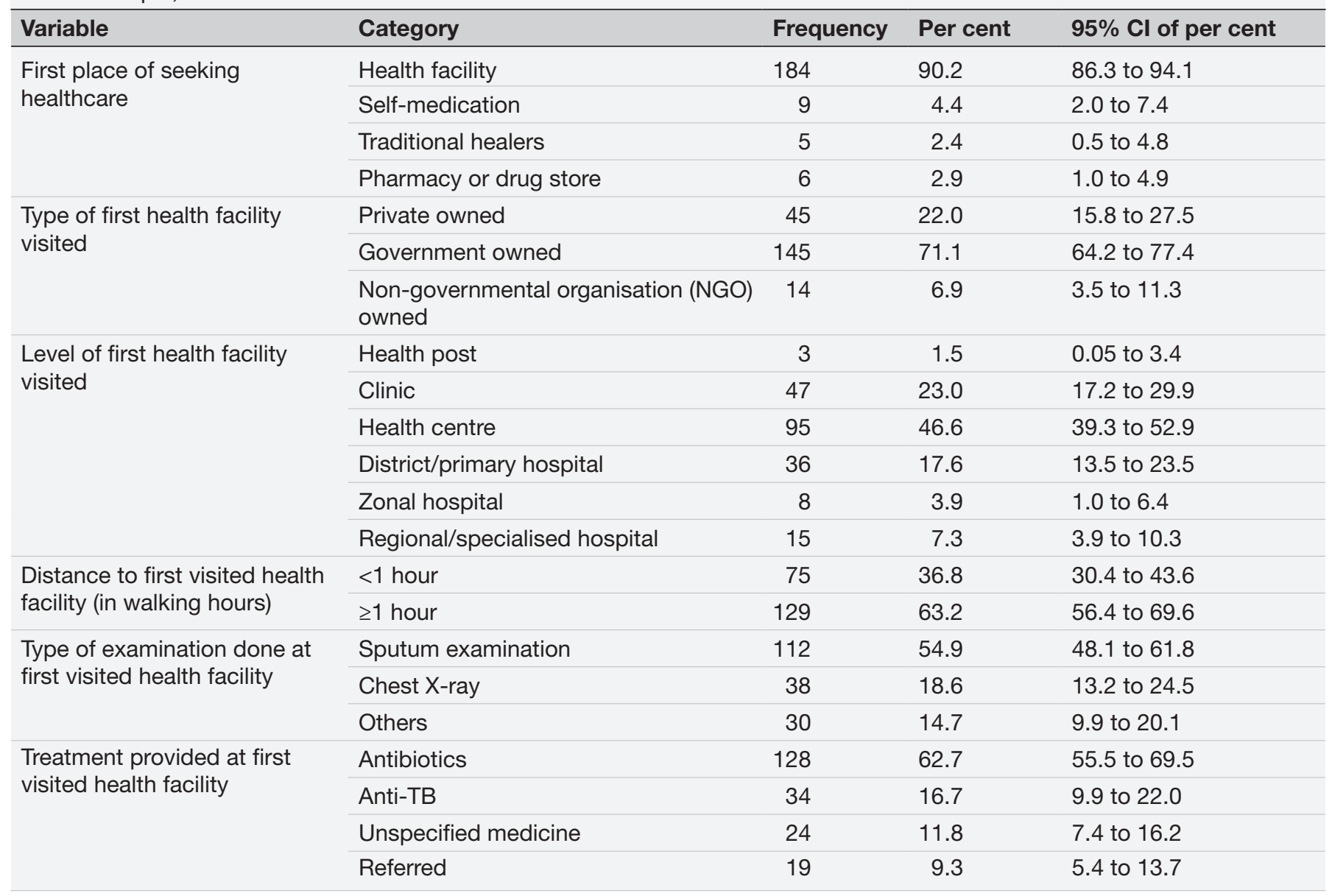

a health facility for the diagnosis of TB (walking hours), more than three-quarters, $170(83.3 \%)$, of the patients travelled for $\geq 1$ hour (table 3 ).

\section{Patient and health system diagnostic delays and associated factors}

Median (IQR) patient delay and health system diagnostic delay were 20 (10-34.5) and 20.5 (8.2-56.2) days, respectively. Results from multivariate logistic regression showed that long patient delays ( $\mathrm{AOR}=2.85$; $95 \% \mathrm{CI}$ : 1.44 to 5.62 ; $\mathrm{p}=0.003$ ) in seeking care and multiple visits to health facilities before diagnosis (AOR=4.95; 95\% CI: 1.98 to 12.40; $\mathrm{p}=0.001$ ) were positively associated with health system diagnostic delays. Provision of sputum smear examination $(\mathrm{AOR}=0.37 ; 95 \% \mathrm{CI}: 0.19$ to $0.75 ; \mathrm{p}=0.005)$ at the first visit to a health facility was negatively associated with health system diagnostic delay. Tables 4 and 5 summarise factors associated with health system diagnostic delays.

\section{DISCUSSION}

The study showed existence of health system diagnostic delay of pulmonary TB diagnosis. The median (IQR) duration of health system diagnostic delay was 20.5 (8.256.2) days. This figure is consistent with a report from a study done in the northern part of Ethiopia. ${ }^{10}$ This similarity could be explained that the vast majority of patients with symptoms of $\mathrm{TB}$ received antibiotics treatment for diseases rather than anti-TB in both studies. However, our finding is longer than other studies conducted elsewhere in Ethiopia. ${ }^{71112}$ On the other hand, several studies $8913-20$ conducted in Ethiopia and other developing countries reported longer median health system delays ranging from 30 to 59 days. The observed difference could be due to methodological differences, such as inadequacy of sample size and/or difference in defining delays.

The study result found that long patient delays before seeking care from a health facility and multiple visits to a health facility before diagnosis of TB were positively associated with long health system diagnostic delay. Provision of sputum smear examination at the first visit to a health facility was negatively associated with long health system diagnostic delay. Accordingly, patients who have delayed in seeking care from a health facility were 2.85 times more likely to experience long health system diagnostic delay compared with their counterparts. This is factual that poor health-seeking behaviour of a patient may extend into overall process of continuum of care at different levels of health system and result in lost to TB 
Table 3 Accessibility and characteristics of health facilities that diagnose new pulmonary tuberculosis (TB) in Gurage and Siltie zones, South Ethiopia, June 2017

\begin{tabular}{|c|c|c|c|c|}
\hline Variable & Category & Frequency & Per cent & $95 \% \mathrm{Cl}$ of per cent \\
\hline \multirow{3}{*}{$\begin{array}{l}\text { Frequency of visit to health facility before diagnosis of } \\
\text { TB }\end{array}$} & $\leq 2$ & 126 & 61.8 & 55.5 to 68.1 \\
\hline & $3-4$ & 62 & 30.4 & 25.0 to 37.7 \\
\hline & $\geq 5$ & 16 & 7.8 & 4.0 to 11.3 \\
\hline \multirow{3}{*}{$\begin{array}{l}\text { Frequency of visit to private health facilities before } \\
\text { diagnosis of TB }\end{array}$} & $\leq 2$ & 188 & 92.1 & 88.2 to 96.0 \\
\hline & $3-4$ & 14 & 6.9 & 3.5 to 10.3 \\
\hline & $\geq 5$ & 2 & 1 & 0.5 to 2.5 \\
\hline \multirow{3}{*}{$\begin{array}{l}\text { Frequency of visit to government health facilities } \\
\text { before diagnosis of TB }\end{array}$} & $\leq 2$ & 169 & 82.8 & 77.5 to 89.2 \\
\hline & $3-4$ & 28 & 13.7 & 8.8 to 18.1 \\
\hline & $\geq 5$ & 7 & 3.4 & 1.0 to 6.8 \\
\hline \multirow{3}{*}{$\begin{array}{l}\text { Frequency of visit to Non-governmental organisation } \\
\text { (NGO)-affiliated health facilities before diagnosis of TB }\end{array}$} & $\leq 2$ & 202 & 99.0 & 97.5 to 99.99 \\
\hline & $3-4$ & 2 & 1.0 & 0.05 to 2.5 \\
\hline & $\geq 5$ & 1 & 0.5 & 0.05 to 1.5 \\
\hline \multirow[t]{3}{*}{ Frequency of visit to clinic before diagnosis of TB } & $\leq 2$ & 189 & 92.6 & 88.8 to 96.1 \\
\hline & $3-4$ & 13 & 6.4 & 2.9 to 9.8 \\
\hline & $\geq 5$ & 2 & 1.0 & 0.3 to 2.9 \\
\hline \multirow{3}{*}{$\begin{array}{l}\text { Frequency of visit to health centre before diagnosis of } \\
\text { TB }\end{array}$} & $\leq 2$ & 186 & 91.2 & 86.8 to 95.0 \\
\hline & $3-4$ & 15 & 7.3 & 3.5 to 11.7 \\
\hline & $\geq 5$ & 3 & 1.5 & 0.5 to 3.4 \\
\hline \multirow{2}{*}{$\begin{array}{l}\text { Frequency of visit to district/primary hospital before } \\
\text { diagnosis of TB }\end{array}$} & $\leq 2$ & 199 & 97.5 & 95.6 to 99.5 \\
\hline & $3-4$ & 5 & 2.4 & 0.5 to 4.4 \\
\hline \multirow{3}{*}{$\begin{array}{l}\text { Frequency of visit to zonal hospital before diagnosis } \\
\text { of TB }\end{array}$} & $\leq 2$ & 199 & 97.5 & 95.6 to 99.9 \\
\hline & $3-4$ & 4 & 2.0 & 0.5 to 3.4 \\
\hline & $\geq 5$ & 1 & 0.5 & 0.1 to 1.5 \\
\hline \multirow{3}{*}{$\begin{array}{l}\text { Frequency of visit to regional/specialised hospital } \\
\text { before diagnosis of TB }\end{array}$} & $\leq 2$ & 201 & 98.5 & 97.1 to 99.9 \\
\hline & $3-4$ & 2 & 1.0 & 0.05 to 2.5 \\
\hline & $\geq 5$ & 1 & 0.5 & 0.03 to 1.5 \\
\hline \multirow[t]{3}{*}{ Types of health facility that diagnosed TB } & Private owned & 27 & 13.2 & 9.4 to 19.0 \\
\hline & $\begin{array}{l}\text { Government } \\
\text { owned }\end{array}$ & 132 & 64.7 & 58.4 to 71.0 \\
\hline & NGO owned & 45 & 22.0 & 15.3 to 27.9 \\
\hline \multirow[t]{5}{*}{ Level of health facility that diagnosed TB } & Clinic & 23 & 11.3 & 6.4 to 16.2 \\
\hline & Health centre & 26 & 12.7 & 8.3 to 18.1 \\
\hline & $\begin{array}{l}\text { District/primary } \\
\text { hospital }\end{array}$ & 77 & 37.7 & 31.0 to 44.1 \\
\hline & Zonal hospital & 37 & 18.1 & 12.3 to 24.0 \\
\hline & $\begin{array}{l}\text { Specialised } \\
\text { hospital }\end{array}$ & 41 & 20.1 & 15.2 to 26.0 \\
\hline \multirow{2}{*}{$\begin{array}{l}\text { Distance to health facility that diagnosed TB (walking } \\
\text { hours) }\end{array}$} & $<1$ hour & 34 & 16.7 & 11.3 to 21.5 \\
\hline & $\geq 1$ hour & 170 & 83.3 & 78.5 to 88.7 \\
\hline \multirow{2}{*}{$\begin{array}{l}\text { Sputum examination done at health facility that } \\
\text { diagnosed TB }\end{array}$} & Yes & 179 & 87.7 & 83.8 to 93.1 \\
\hline & No & 25 & 12.2 & 6.9 to 16.2 \\
\hline \multirow[t]{2}{*}{ Chest X-ray done at health facility that diagnosed TB } & Yes & 140 & 68.6 & 62.8 to 75.0 \\
\hline & No & 64 & 31.3 & 25.2 to 37.2 \\
\hline
\end{tabular}


Table 4 Bivariate logistic regression results: factors associated with health system diagnostic delays of new pulmonary tuberculosis (TB) in Gurage and Siltie zones, South Ethiopia, June 2017

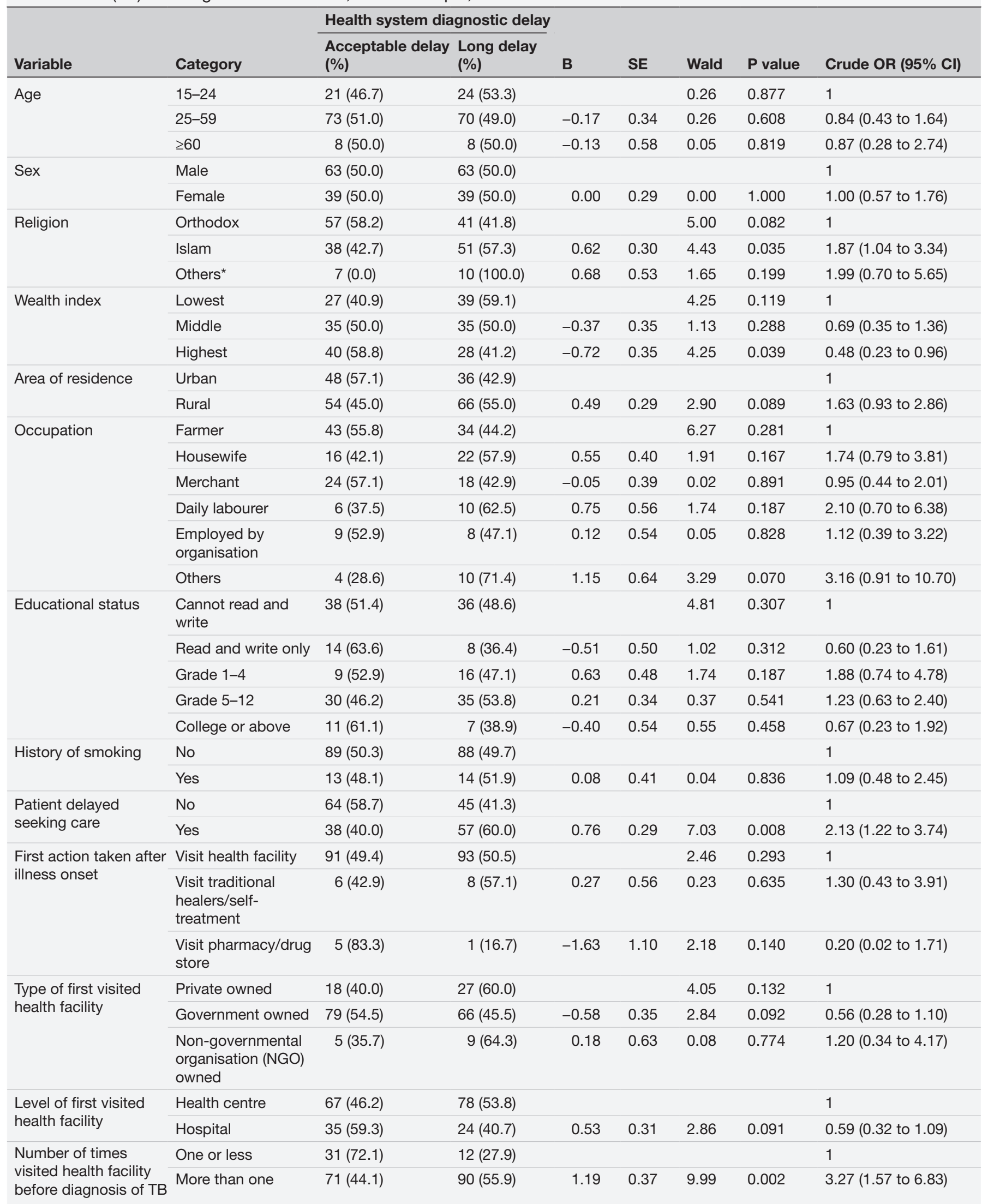

Continued 
Table 4 Continued

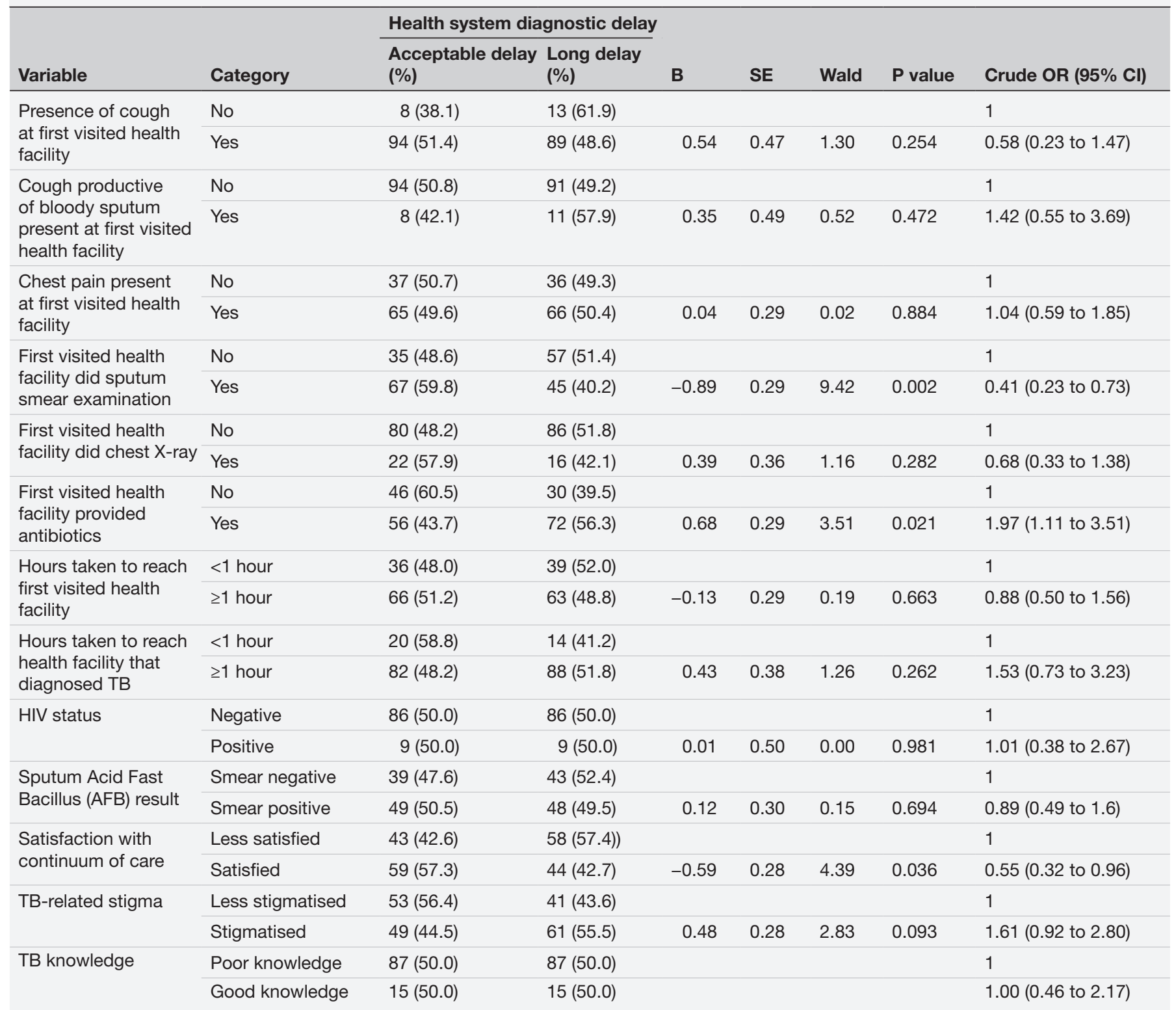

*Includes Catholic and Protestant Christians.

diagnostic follow-up. Consequently, patients who have lost to follow-up in TB diagnosis process might also experience delayed diagnosis of the disease. A study done in Northern Ethiopia reported a positive association between patient delay and health system delay in TB treatment. ${ }^{21}$ A similar result was also reported from Tanzania. ${ }^{22}$

Multiple health facility visits before diagnosis of TB significantly contributed for long health system diagnostic delay. Accordingly, this study found that patients who visited a health facility more than one time prior to diagnosis of TB were five times more likely to experience health system diagnostic delay than their counterparts. Several studies in Ethiopia and abroad have reported a similar finding. ${ }^{11} 1315182023$ This might be due to the fact that patients who have multiple health facility visits might have switched between health providers, which may delay the diagnosis of the disease. Moreover, in this study, merely $16.8 \%$ patients received anti-TB treatment at their first contact with a health facility. This implies the existence of health system delay in diagnosis of TB. The observed association could also be due to the type of the health facility. Patients who made first visit to hospitals were approximately 3.73 times more likely to get anti-TB treatment during their first visit as compared with patients who visited at lower level health facilities like health posts, health centres and clinics. This is due to the fact that hospitals are better equipped with laboratories and skilled manpower for diagnosis and treatment of TB than health posts, health centres and clinics.

Patients who received sputum smear examination at the first contact with a health facility were $63 \%$ less likely to experience health system diagnostic delay as 
Table 5 Multivariate logistic results: factors associated with health system diagnostic delays of new pulmonary tuberculosis (TB) in Gurage and Siltie zones, South Ethiopia, June 2017

\begin{tabular}{|c|c|c|c|c|c|c|c|c|}
\hline \multirow[b]{2}{*}{ Variable } & \multirow[b]{2}{*}{ Category } & \multicolumn{2}{|c|}{$\begin{array}{l}\text { Health system diagnostic } \\
\text { delay }\end{array}$} & \multirow{2}{*}{ B } & \multirow[b]{2}{*}{ SE } & \multirow[b]{2}{*}{ Wald } & \multirow[b]{2}{*}{$P$ value } & \multirow[b]{2}{*}{$\begin{array}{l}\text { Adjusted OR (95\% } \\
\text { Cl) }\end{array}$} \\
\hline & & $\begin{array}{l}\text { Acceptable } \\
\text { delay (\%) }\end{array}$ & $\begin{array}{l}\text { Long delay } \\
(\%)\end{array}$ & & & & & \\
\hline \multirow[t]{3}{*}{ Religion } & Orthodox & 57 (58.2) & $41(41.8)$ & & & 2.96 & 0.228 & 1 \\
\hline & Islam & $38(42.7)$ & $51(57.3)$ & 0.54 & 0.35 & 2.47 & 0.116 & 1.72 (0.87 to 3.40$)$ \\
\hline & Others ${ }^{*}$ & $7(41.2)$ & $10(58.8)$ & 0.66 & 0.61 & 1.18 & 0.277 & 1.93 (0.59 to 6.36$)$ \\
\hline \multirow[t]{3}{*}{ Wealth index } & Lowest & 27 (40.9) & $39(59.1)$ & & & 1.69 & 0.430 & 1 \\
\hline & Middle & $35(50.0)$ & $35(50.0)$ & -0.43 & 0.43 & 0.99 & 0.318 & 0.65 (0.28 to 1.51$)$ \\
\hline & Highest & $40(58.8)$ & $28(41.2)$ & -0.82 & 0.66 & 1.53 & 0.215 & 0.44 (0.12 to 1.62$)$ \\
\hline \multirow[t]{2}{*}{ Area of residence } & Urban & 48 (57.1) & 36 (42.9) & & & & & 1 \\
\hline & Rural & $54(45.0)$ & $66(55.0)$ & 0.06 & 0.56 & 0.12 & 0.912 & $1.06(0.33$ to 3.21$)$ \\
\hline \multirow{2}{*}{$\begin{array}{l}\text { Patient delayed } \\
\text { seeking care }\end{array}$} & No & $64(58.7)$ & $45(41.3)$ & & & & & 1 \\
\hline & Yes & $38(40.0)$ & $57(60.0)$ & 1.05 & 0.35 & 9.09 & 0.003 & 2.85 (1.44 to 5.62$) \dagger$ \\
\hline \multirow{3}{*}{$\begin{array}{l}\text { Type of first } \\
\text { visited health } \\
\text { facility }\end{array}$} & Private owned & $18(40.0)$ & $27(60.0)$ & & & 3.74 & 0.154 & 1 \\
\hline & Government owned & $79(54.5)$ & $66(45.5)$ & -0.32 & 0.42 & 0.54 & 0.463 & 0.73 (0.32 to 1.68$)$ \\
\hline & $\begin{array}{l}\text { Non-governmental } \\
\text { organisation (NGO) } \\
\text { owned }\end{array}$ & $5(35.7)$ & $9(64.3)$ & 1.00 & 0.87 & 1.35 & 0.246 & 2.73 (0.50 to 14.98$)$ \\
\hline \multirow{2}{*}{$\begin{array}{l}\text { Level of first } \\
\text { visited health } \\
\text { facility }\end{array}$} & Health centre & $67(46.2)$ & 78 (53.8) & & & & & 1 \\
\hline & Hospital & $35(59.3)$ & $24(40.7)$ & -0.39 & 0.44 & 0.79 & 0.374 & 0.67 (0.28 to 1.61$)$ \\
\hline \multirow{2}{*}{$\begin{array}{l}\text { Number of times } \\
\text { visited health } \\
\text { facility before } \\
\text { diagnosis of TB }\end{array}$} & One or less & $31(72.1)$ & $12(27.9)$ & & & & & \\
\hline & More than one & $71(44.1)$ & $90(55.9)$ & 1.60 & 0.47 & 1.70 & 0.001 & 4.95 (1.98 to 12.40$) \dagger$ \\
\hline \multirow{2}{*}{$\begin{array}{l}\text { First visited } \\
\text { health facility did } \\
\text { sputum smear } \\
\text { examination }\end{array}$} & No & $35(48.6)$ & $57(51.4)$ & & & & & 1 \\
\hline & Yes & $67(59.8)$ & $45(40.2)$ & -0.99 & 0.35 & 7.74 & 0.005 & $0.37(0.19$ to 0.75$) \dagger$ \\
\hline \multirow{2}{*}{$\begin{array}{l}\text { First visited health } \\
\text { facility provided } \\
\text { antibiotics }\end{array}$} & No & $46(60.5)$ & $30(39.5)$ & & & & & 1 \\
\hline & Yes & $56(43.7)$ & $72(56.3)$ & 0.43 & 0.35 & 1.44 & 0.230 & 1.53 (0.76 to 3.07$)$ \\
\hline \multirow{2}{*}{$\begin{array}{l}\text { Satisfaction of on } \\
\text { continuum of care }\end{array}$} & Less satisfied & $43(42.6)$ & $58(57.4))$ & & & & & 1 \\
\hline & Satisfied & $59(57.3)$ & $44(42.7)$ & -0.48 & 0.35 & 1.90 & 0.168 & 0.62 (0.31 to 1.22$)$ \\
\hline \multirow[t]{2}{*}{ TB-related stigma } & Less stigmatised & $53(56.4)$ & $41(43.6)$ & & & & & 1 \\
\hline & Stigmatised & $49(44.5)$ & $61(55.5)$ & 0.36 & 0.36 & 1.02 & 0.311 & 1.44 (0.71 to 2.90$)$ \\
\hline
\end{tabular}

*Includes Catholic and Protestant Christians.

†Statistically significant at $p$ value less than 0.05 .

compared with their counterparts. The existing evidence showed that a sputum smear test is sensitive to detect infectious smear-positive pulmonary TB. $^{24}$ Our study result supported this evidence, where we found a negative association between early sputum smear examination and long health system diagnostic delays. Likewise, a study found that early ordering of a TB diagnostic test by health providers significantly reduced diagnostic delay irrespective of the qualification of the health providers. ${ }^{25}$ It is also found that improving diagnostic accuracy of a $\mathrm{TB}$ test without reducing time to test does not reduce diagnostic delay. ${ }^{25}$ An early sputum smear test might have enhanced early diagnosis of the disease in this study. It is recommended that sputum smear examination should precede other tests for diagnosis of pulmonary $\mathrm{TB},{ }^{24}$ probably because of its affordability at different levels of healthcare system. Ensuring availability of quality sputum smear examination at all levels of healthcare system within the study settings might significantly reduce health system diagnostic delay and enhance early containment of infectious pulmonary TB. Unfortunately, a significant 
proportion $(45.1 \%)$ of studied patients did not receive sputum smear examination at their first visit to a health facility.

In this study, a sizeable proportion $(43.7 \%)$ of patients received non-mycobacterial antibiotics at their first contact with a health facility. However, evidence suggested that inappropriate prescription of antibiotics is a global problem and associated with adverse effect, more frequent reattendance and increased medication of self-limiting medical conditions and also predisposes to antimicrobial resistance. ${ }^{26}$ Similarly, finding of a study done in British Columbia ${ }^{27}$ and a systematic review and meta-analysis done by Chen et $a l^{8}$ showed that prior exposure to antibiotics was associated with health system diagnostic delays of TB. On the other hand, a study done in Tanzania reported a negative association of prior use of medication before diagnosis of TB and health system diagnostic delay of TB. ${ }^{29}$ However, in this study, we found no association between prior antibiotics use and health system diagnostic delay.

Previous studies found a positive association between health system delay in diagnosis of $\mathrm{TB}$ and female gender, ${ }^{12} 181923$ first consultation of primary care facilities, ${ }^{8} 111621$ first consultation of private facilities/ providers, ${ }^{81015192023}$ low economic status, ${ }^{18}$ HIV negative status ${ }^{11}{ }^{14}$ and older age. ${ }^{19}$ However, we did not find an association between these factors and health system diagnostic delay.

This study has several limitations that readers should take into consideration when interpreting the findings. Data collectors were health professionals working in TB units of participating health facilities. As patients might believe their response might negatively affect care provided and/or health professionals expected socially desired response, the patients may have provided misleading response about TB-related stigma, delays, quality of healthcare and health-seeking behaviours. This might have introduced reporting bias like social desirability bias. However, the same procedures were followed in collecting data from all patients and therefore differential reporting may not happen to groups to be compared. Data about delays and continuum of healthcare were collected based on patients' recall; hence, recall bias might have compromised accurate reporting of duration of illnesses and continuum of healthcare received. This limitation is particularly of concern for patients with longer delays compared with shorter delays. There are no universally accepted ways of assessing TB-related stigma, service satisfaction and knowledge about TB. We reviewed literature and designed items to assess TB-related stigma, service satisfaction and knowledge about TB. However, the extent of reliability of these items is not known. Similarly, there are no universally accepted and standardised ways of classifying diagnostic delay into acceptable and long delays. Previous studies used different cut-off points to dichotomise diagnostic delay into acceptable and long delays. In the current study, we used median delay as a cutoff point to dichotomise diagnostic delay as acceptable and long delay, and the reliability of this classification is not known.

\section{CONCLUSIONS}

A considerable proportion of patients with TB experience long health system diagnostic delay, which facilitates the disease transmission to their families, neighbours and communities. Long patient delay and multiple health facility visits are positively associated with long health system TB diagnostic delay; whereas sputum smear examination at the first contact with a health facility is negatively associated with long health system TB diagnostic delay. Therefore, the regional health bureau and national ministry of health should strengthen early detection/ diagnosis of TB. Future studies should focus to elucidate how multiple health facility visits and patient delays would contribute to health system TB diagnostic delay.

Acknowledgements We are very grateful to Wolkite University College of Health Sciences for funding this research. We are also grateful to all study participants for their willingness to participate and for their precious time. We are very thankful to supervisors and data collectors for their hard work. Lastly, but not the least, our thanks go to all people who helped us in accomplishing this research, especially zonal government officials.

Contributors WGW conceived the project, developed the proposal, did data analysis and interpretation, and wrote the manuscript. WGW acted as a guarantor. $\mathrm{AW}$ and $\mathrm{AF}$ developed the proposal, did data analysis and interpretation, and wrote the manuscript. ZW did data analysis and interpretation, and wrote the manuscript. All authors read and approved the final manuscript.

Funding This research was financed by Wolkite University College of Medicine and Health Sciences. Grant number wrd/124/09

Disclaimer The funder did not have any role in design of the study, data collection, analysis, interpretation, writing the manuscript and decision to publish.

\section{Competing interests None declared.}

Patient and public involvement Patients and/or the public were not involved in the design, or conduct, or reporting, or dissemination plans of this research.

\section{Patient consent for publication Not required.}

Ethics approval The questionnaire did not have personal identifiers. Informed verbal consent was obtained from all participants during data collection. Informed verbal consent was obtained from legal guardians for respondents less than 18 years of age. Informed verbal consent was obtained and recorded by data collector at the time of the interview. Use of verbal consent was approved by an ethical committee. Participants were informed of the purpose of the research and their full autonomy to decide whether to participate or not. Participants were also informed that their decision to participate or not does not affect health service provided to them by whatever means. Ethical clearance was obtained from the institutional ethical review board of Wolkite University and letter of cooperation was obtained from two zonal administrations and participating health facilities.

Provenance and peer review Not commissioned; externally peer reviewed.

Data availability statement Data are available upon reasonable request. What is already known on this subject?Studies done in Ethiopia showed that delay in tuberculosis diagnosis and treatment is one of major challenges to tuberculosis control program in the country. Previous studies found an association between health system delay and female gender, first consultation of primary care facilities, first consultation of private facilities, low economic status, HIV negative status and older age. A health system delay is believed to be more amenable to policy intervention than patient delay. In this study we focused on health system factors that might associate with health system diagnostic delay. What does this study add?We found that sputum smear examination at the first visit to health facility has negative association with health system diagnostic delay. Similarly first consultation to hospital instead of lower level facilities, early sputum smear and chest X-ray examinations have positive association with initiation of anti-TB treatment at the first contact with health facility. Ensuring availability of quality sputum smear 
and chest X-ray examinations to at all levels of health system might significantly improve early diagnosis and prompt treatment pulmonary tuberculosis.

Open access This is an open access article distributed in accordance with the Creative Commons Attribution Non Commercial (CC BY-NC 4.0) license, which permits others to distribute, remix, adapt, build upon this work non-commercially, and license their derivative works on different terms, provided the original work is properly cited, appropriate credit is given, any changes made indicated, and the use is non-commercial. See: http://creativecommons.org/licenses/by-nc/4.0/.

ORCID iD

Wako Golicha Wako http://orcid.org/0000-0002-4438-4304

\section{REFERENCES}

1 Longo DL, Fauci AS, Kasper DL. Harrison's principles of internal medicine. 18th edn. McGraw-Hill, 2011.

2 World Health Organization. Global tuberculosis report 2020, 2020.

3 United Nations. Transforming our world: the 2030 agenda for sustainable development, 2015.

4 Kompala T, Shenoi SV, Friedland G. Transmission of tuberculosis in resource-limited settings. Curr HIVIAIDS Rep 2013;10:264-72.

5 Yuen CM, Amanullah F, Dharmadhikari A, et al. Turning off the TAP: stopping tuberculosis transmission through active case-finding and prompt effective treatment. Lancet 2015;386:15:2334-43.

6 Cheng S, Chen W, Yang Y, et al. Effect of diagnostic and treatment delay on the risk of tuberculosis transmission in Shenzhen, China: an observational cohort study, 1993-2010. PLoS One 2013;8:e67516.

7 Gele AA, Bjune G, Abebe F. Pastoralism and delay in diagnosis of TB in Ethiopia. BMC Public Health 2009;9:5

8 Belay M, Bjune G, Ameni G, et al. Diagnostic and treatment delay among tuberculosis patients in afar region, Ethiopia: a crosssectional study. BMC Public Health 2012;12:369.

9 Wondimu T, W/Michael K, Kassahun W, et al. Delay in initiating tuberculosis treatment and factors associated among pulmonary tuberculosis patients in East Wollega, Western Ethiopia. Ethiop $J$ Health Dev 2007;21:148-56.

10 Yimer S, Bjune G, Alene G. Diagnostic and treatment delay among pulmonary tuberculosis patients in Ethiopia: a cross sectional study. BMC Infect Dis 2005;5:112.

11 Bogale S, Diro E, Shiferaw AM, et al. Factors associated with the length of delay with tuberculosis diagnosis and treatment among adult tuberculosis patients attending at public health facilities in Gondar town, Northwest Ethiopia. BMC Infect Dis 2017;17:145.

12 Asefa A, Teshome W. Total delay in treatment among smear positive pulmonary tuberculosis patients in five primary health centers, southern Ethiopia: a cross sectional study. PLoS One 2014;9:e102884.
13 Osei E, Akweongo P, Binka F. Factors associated with DELAY in diagnosis among tuberculosis patients in Hohoe Municipality, Ghana. BMC Public Health 2015;15:721.

14 Ngangro NN, Ngarhounoum D, Ngangro MN, et al. Pulmonary tuberculosis diagnostic delays in Chad: a multicenter, hospital-based survey in Ndjamena and Moundou. BMC Public Health 2012;12:513.

15 Sreeramareddy CT, Qin ZZ, Satyanarayana S, et al. Delays in diagnosis and treatment of pulmonary tuberculosis in India: a systematic review. Int J Tuberc Lung Dis 2014;18:255-66.

16 Makwakwa L, Sheu M-ling, Chiang C-Y, et al. Patient and heath system delays in the diagnosis and treatment of new and retreatment pulmonary tuberculosis cases in Malawi. BMC Infect Dis 2014;14:132.

17 Maciel ELN, Golub JE, Peres RL, et al. Delay in diagnosis of pulmonary tuberculosis at a primary health clinic in Vitoria, Brazil. Int $J$ Tuberc Lung Dis 2010;14:11:1403-10.

18 Bonadonna LV, Saunders MJ, Zegarra R, et al. Why wait? The social determinants underlying tuberculosis diagnostic delay. PLoS One 2017;12:e0185018.

19 Ben Amar J, Hassairi M, Ben Salah N, et al. Pulmonary tuberculosis: diagnostic delay in Tunisia. Med Mal Infect 2016;46:79-86.

20 Paramasivam S, Thomas B, Chandran P, et al. Diagnostic delay and associated factors among patients with pulmonary tuberculosis in Kerala. J Family Med Prim Care 2017;6:643-8.

21 Tedla K, Medhin G, Berhe G, et al. Factors associated with treatment initiation delay among new adult pulmonary tuberculosis patients in Tigray, Northern Ethiopia. PLoS One 2020;15:e0235411.

22 Mhalu G, Weiss MG, Hella J, et al. Explaining patient delay in healthcare seeking and loss to diagnostic follow-up among patients with presumptive tuberculosis in Tanzania: a mixed-methods study. BMC Health Serv Res 2019;19:217.

23 Needham DM, Foster SD, Tomlinson G, et al. Socio-economic, gender and health services factors affecting diagnostic delay for tuberculosis patients in urban Zambia. Trop Med Int Health 2001;6:256-9.

24 Anastasios Konstantinos. Testing for tuberculosis. Australian Prescriber 2010;33:12-18.

25 Deo S, Singh S, Jha N, et al. Predicting the impact of patient and private provider behavior on diagnostic delay for pulmonary tuberculosis patients in India: a simulation modeling study. PLOS Med 2020;17:e1003039.

26 Llor C, Bjerrum L. Antimicrobial resistance: risk associated with antibiotic overuse and initiatives to reduce the problem. Ther Adv Drug Saf 2014;5:229-41.

27 Wang M, Marra C, Elwood RK. Marra F use of antibiotics delays diagnosis of tuberculosis. Am J Res Crit Care Med 2010;181:A1790.

28 Chen T-C, Lu P-L, Lin C-Y, et al. Fluoroquinolones are associated with delayed treatment and resistance in tuberculosis: a systematic review and meta-analysis. Int J Infect Dis 2011;15:e211-6.

29 Said K, Hella J, Mhalu G, et al. Diagnostic delay and associated factors among patients with pulmonary tuberculosis in Dar ES Salaam, Tanzania. Infect Dis Poverty 2017;6:64. 